EXTENDED REPORT

\title{
Refractive adaptation in amblyopia: quantification of effect and implications for practice
}

\author{
C E Stewart, M J Moseley, A R Fielder, D A Stephens, and the MOTAS cooperative
}

Br J Ophthalmol 2004;88:1552-1556. doi: 10.1136/bjo.2004.044214

See end of article for authors' affiliations .....................

Correspondence to: Dr Catherine Stewart, Department of Visual Neuroscience, Imperial College London, Charing Cross Campus, Margravine Road, London W6 8RP, UK; c.stewart@ imperial.ac.uk

Accepted for publication 31 May 2004

\begin{abstract}
Aim: To describe the visual response to spectacle correction ("refractive adaptation") for children with unilateral amblyopia as a function of age, type of amblyopia, and category of refractive error.

Method: Measurement of corrected amblyopic and fellow eye logMAR visual acuity in newly diagnosed children. Measurements repeated at 6 weekly intervals for a total 18 weeks.

Results: Data were collected from 65 children of mean (SD) age 5.1 (1.4) years with previously untreated amblyopia and significant refractive error. Amblyopia was associated with anisometropia in 18 (5.5 (1.4) years), strabismus in 16 (4.2 (0.98) years), and mixed in 31 (5.2 (1.5) years) of the study participants. Mean (SD) corrected visual acuity of amblyopic eyes improved significantly $(p<0.001)$ from $0.67(0.38)$ to 0.43 (0.37) logMAR: a mean improvement of 0.24 (0.18), range $0.0-0.6$ log units. Change in logMAR visual acuity did not significantly differ as a function of amblyopia type $(p=0.29)$ (anisometropia 0.22 (0.13); mixed $0.18(0.14)$; strabismic $0.30(0.24)$ ) or for age $(p=0.38)$ ("under 4 years" $0.23(0.18)$; "4-6 years" 0.24 (0.20); "over 6 years" $0.16(0.23)$.

Conclusion: Refractive adaptation is a distinct component of amblyopia treatment. To appropriately evaluate mainstream therapies such as occlusion and penalisation, the beneficial effects of refractive adaptation need to be fully differentiated. A consequence for clinical practice is that children may start occlusion with improved visual acuity, possibly enhancing compliance, and in some cases unnecessary patching will be avoided.
\end{abstract}

A mblyopia is the commonest childhood vision disorder with an estimated prevalence of $1.6-3.5 \%{ }^{1}$ This developmental anomaly is characterised by a loss of spatial vision (usually unilateral) in the presence of strabismus, refractive error (bilateral ametropia or anisometropia), and/or form deprivation. The defining loss of resolution in amblyopia cannot immediately be alleviated by refractive correction even when the sole amblyopic association is ametropia. None the less, it is accepted that correction of refractive error, particularly in those with anisometropic amblyopia $^{2-5}$ can, over a period of weeks, reduce the visual deficit-a phenomenon we have termed refractive adaption. ${ }^{4}$ The mechanism which underpins this period of improvement remains unclear although a non-competitive, activity dependent process may be implicated. ${ }^{46}$

Refractive correction is a necessary component of most cases of amblyopia therapy and, where indicated, it is typically prescribed together with mainstream therapies such as occlusion and penalisation. Perhaps because of the presumed urgency of treating the condition, both therapeutic components tend to be prescribed simultaneously or in close temporal proximity. Yet there is evidence that a successful period of refractive adaptation may fully correct the visual deficit and pre-empt the need for further treatment, ${ }^{4}$ and, even where this is not the case, limited improvement may still enhance concordance with occlusion therapy. From the perspective of treatment evaluation, prescribing a refractive correction at the same time as another therapy militates against differentiating their relative contributions to the eventual visual outcome.

The present study examines the phenomenon of refractive adaptation, specifically with regard to its influence as a function of age, type of amblyopia, and refractive error. The analysis utilises the dataset of the Monitored Occlusion Treatment of Amblyopia Study-a recently reported investigation of the dose-response function of amblyopia therapy that included non-overlapping phases of refractive adaptation and occlusion therapy. ${ }^{7}$

\section{METHODS}

\section{Study design}

The Monitored Occlusion Treatment for Amblyopia Study (MOTAS) sought to determine the dose-response function of occlusion therapy for the treatment of amblyopia in childhood. The design and principal findings have been reported separately elsewhere. ${ }^{78}$

Children were recruited from two London hospitals between January 2000 and December 2001. Ethical approval was sought and obtained from the two local research ethics committees. Inclusion eligibility criteria were 3-8 years of age; anisometropia and/or strabismus; an interocular acuity difference of at least $0.1 \log$ MAR; and no history of previous amblyopia treatment (includes spectacle wear or occlusion), or ocular pathology or learning difficulties. Rationale for inclusion criteria are discussed elsewhere. ${ }^{7}$ Anisometropia was defined as 1.00D or more difference in refractive error between the two eyes. A diagnosis of strabismus was given in all cases of manifest strabismus for near and/or distance fixation including those with microtropia with identity where the presence of eccentric fixation was the only sign of strabismus.

The principal design components of MOTAS were a phase of refractive adaptation (for those children with refractive error) followed by a phase of occlusion. The duration of the former was of a fixed 18 week duration: a period adopted on the basis of a recent study ${ }^{4}$ indicating that no clinically significant gains (that is, $>0.10 \log$ MAR) occurred beyond this time. The occlusion phase was of variable duration depending upon an algorithm to detect "stability" of visual outcome (that is, the best visual outcome likely to have been achieved for any given child). Here, we report only upon 


\begin{tabular}{l} 
Table 1 Criteria for clinically significant \\
refractive error \\
\hline 21.50Ds bilateral hypermetropia \\
1.50Ds bilateral myopia \\
$\geqslant 0.75 \mathrm{Dc}$ bilateral astigmatism \\
All astigmatism in combination with significant \\
hypermetropia \\
$\geqslant 1.00$ Ds anisometropia \\
Full astigmatic, anisometropic myopic and mild/moderate \\
hypermetropic (+1.50 Ds to $+5.00 \mathrm{Ds}$ ) refractive errors were \\
prescribed. Prescriptions for high hypermetropes are given \\
within $2.00 \mathrm{Ds}$ of the full correction. \\
\end{tabular}

visual outcome at the end of the of refractive adaptation phase.

Prescription of spectacle correction was based on a strict refraction protocol (table 1). Refractive adaptation began approximately 14 days after the initial assessment and determination of stable baseline measures (allowing for delivery of spectacles from the child's own dispensing optician). At the first visit of the refractive adaptation phase (week 0), visual performance was recorded with and without refractive correction. Previous instruction had been given that spectacles were not to be worn in the intervening period between delivery and clinic attendance. Children and parents were advised of the need for spectacles to be worn full time and a schedule of three vision assessments at 6 weekly intervals instigated (weeks 6, 12, and 18).

The primary visual function outcome measure was $\log$ MAR visual acuity. ${ }^{10}$ Three $\log$ MAR visual acuity charts were employed: ETDRS (manufacturer precision vision), crowded (Keeler Ltd), and uncrowded (Keeler Ltd) logMAR charts. Standard protocols for visual acuity testing were used and were scored by letter. The type of chart used depended on the reading ability of the child, and was generally age dependent. If a child was able to undertake a more difficult test as they progressed through the trial, the initial test(s) remained in that child's test battery. The outcome measure of most importance was considered to be the visual acuity of the amblyopic eye, hence this was recorded first at the start of every visit in case the child became fatigued.

Kruskal-Wallis one way analysis of variance on ranks was used to detect differences in response to refractive adaptation with respect to age, type of amblyopia, and refractive error. Classification of strabismus was not used as a factor as the numbers of each group were too small. Multiple testing dictated that only $\mathrm{p}$ values $<0.01$ were deemed significant. Visual acuities are expressed in logMAR and change in acuities in $\log$ units. Power of $80 \%$ is given to detect a significant difference of $0.20 \log$ units with $n \geqslant 16$ (smallest $n$ in analysis), variance 0.20 , and $\alpha=0.01$. It should be noted therefore with the numbers of subjects in each age, amblyopia type, and refractive error group that there is less power to detect differences $<0.20 \log$ units.

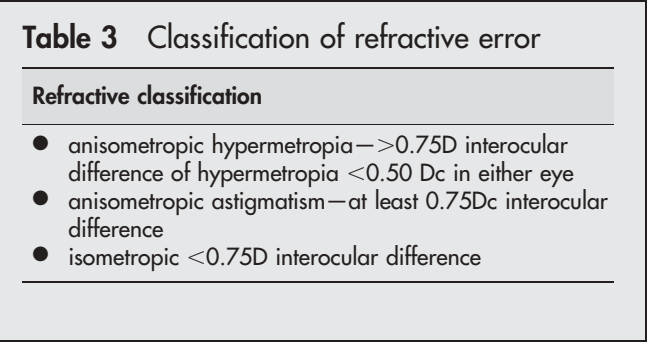

\section{RESULTS}

With parental written consent, 65 children of mean (SD) age 5.1 (1.4) years with previously untreated amblyopia and significant refractive error were recruited. Amblyopia was associated with anisometropia in 18 (mean age 5.5 (1.4) years) participants, strabismus in 16 (mean age 4.2 (0.98) years), and both anisometropia and strabismus in 31 (mean age 5.2 (1.5) years). For amblyopic eyes, mean (SD) visual acuity at recruitment was $0.77(0.41)$ and ranged from 0.1 to 1.6 logMAR. Mean (SD) visual acuity in the fellow eyes was $0.15(0.1)$ and ranged from -0.05 to 0.4 . The number of data sets at the $0,6,12$, and 18 weeks assessment were $49,50,47$, and 52 , respectively.

\section{Distribution of refractive errors}

Mean (SD) (spherical error (dioptres) for the amblyopic and fellow eyes was $+4.0(2.1)$ and +2.7 (1.8), respectively. Astigmatism was present in 41 (63\%) with a mean (SD) cylindrical error of -0.91 (1.00) for amblyopic eyes and $-0.45(0.62)$ for fellow eyes. Distribution of refractive error according to amblyopia type is shown in table 2. Mean (SD) anisometropia was 1.47 (1.56) for the whole group and 1.97 (1.03), $0.32(0.34)$ and $1.66(2.11)$ for amblyopia associated with anisometropia, strabismus, and mixed amblyopia, respectively.

Participants were categorised according to type of refractive error: anisometropic hypermetropia, anisometropic astigmatism, isometropic. Details of the classification scheme are shown in table 3, and the mean refractive error of each group is provided in table 4 .

\section{Distribution of strabismus}

Details of the classification of strabismus for those in the strabismic amblyopia and mixed amblyopia groups are provided in table 5 .

\section{Response to spectacle wear \\ Amblyopic eyes}

The mean (SD) uncorrected vision of amblyopic eyes at week 0 refractive adaptation was $0.77(0.40)$. Mean (SD) corrected visual acuity of amblyopic eyes improved significantly $(\mathrm{p}<0.001)$ from $0.67(0.40)$ at week 0 to $0.43(0.37)$ after 18 weeks of spectacle wear: a mean improvement of 0.24 (0.18), range 0.00 to $0.60 \log$ units (fig 1 and table 6). Eight

Table 2 Mean (SD) refractive error and cylinder axis range

\begin{tabular}{|c|c|c|c|c|c|}
\hline & & All groups & Anisometropia & Strabismus & Mixed \\
\hline \multirow[t]{4}{*}{ Amblyopic eye } & Mean sphere & $4.0(2.1)$ & $3.8(1.9)$ & $3.65(1.50)$ & $4.50(2.4)$ \\
\hline & Range sphere & +9.00 to -4.00 & +7.50 to -4.00 & +6.50 to +0.75 & +9.00 to -4.00 \\
\hline & Mean cylinder & $-0.91(1.0)$ & $-0.98(1.2)$ & $-0.90(0.98)$ & $-1.00(0.77)$ \\
\hline & Range cylinder & 0 to -3.50 & 0 to -3.50 & 0 to -3.50 & 0 to -2.50 \\
\hline \multirow[t]{4}{*}{ Fellow eye } & Mean sphere & $2.7(1.8)$ & $1.99(1.46)$ & $3.33(1.51)$ & $2.85(2.04)$ \\
\hline & Range sphere & +6.50 to 0 & +6.50 to 0 & +6.00 to +0.75 & +6.50 to 0 \\
\hline & Mean cylinder & $-0.45(0.62)$ & $-0.30(0.33)$ & $-0.64(0.99)$ & $-0.45(0.62)$ \\
\hline & Range cylinder & 0 to -3.00 & 0 to -3.00 & 0 to -3.00 & 0 to -1.50 \\
\hline
\end{tabular}


Table 4 Mean (SD) refractive error and cylinder axis range for refractive error categories

\begin{tabular}{|c|c|c|c|c|c|}
\hline & & All groups & $\begin{array}{l}\text { Anisometropic } \\
\text { hypermetropia } \\
(n=29)\end{array}$ & $\begin{array}{l}\text { Anisometropic } \\
\text { astigmatism } \\
(\mathrm{n}=19)\end{array}$ & $\begin{array}{l}\text { Isometropia } \\
\text { ( } n=18)\end{array}$ \\
\hline \multirow[t]{4}{*}{ Amblyopic eye } & Mean sphere & $4.0(2.1)$ & $4.51(1.9)$ & $4.34(2.7)$ & $3.69(1.64)$ \\
\hline & Range sphere & +9.00 to -4.00 & +9.00 to +2.00 & +7.75 to -4.00 & +6.50 to +0.75 \\
\hline & Mean cylinder & $-0.91(1.0)$ & $-0.45(0.29)$ & $-1.4(0.87)$ & $-1.1(0.85)$ \\
\hline & Range cylinder & 0 to 3.50 & 0 to 0.50 & 0.75 to 3.25 & 0 to 3.50 \\
\hline \multirow[t]{4}{*}{ Fellow eye } & Mean sphere & $2.7(1.8)$ & $2.19(1.19)$ & $2.67(1.35)$ & $3.37(1.65)$ \\
\hline & Range sphere & +6.50 to 0.00 & +6.00 to +0.00 & +6.50 to +0.00 & +6.00 to +0.75 \\
\hline & Mean cylinder & $-0.45(0.62)$ & $-0.13(0.19)$ & $-0.71(0.33)$ & $-0.71(0.88)$ \\
\hline & Range cylinder & 0 to 3.00 & 0 to 0.50 & 0.75 to 1.25 & 0 to 3.00 \\
\hline
\end{tabular}

Table 5 Classification of subjects with manifest strabismus (includes those with mixed amblyopia). Mean (SD) of angle of deviation at near and distance fixation with and without correction at week 0

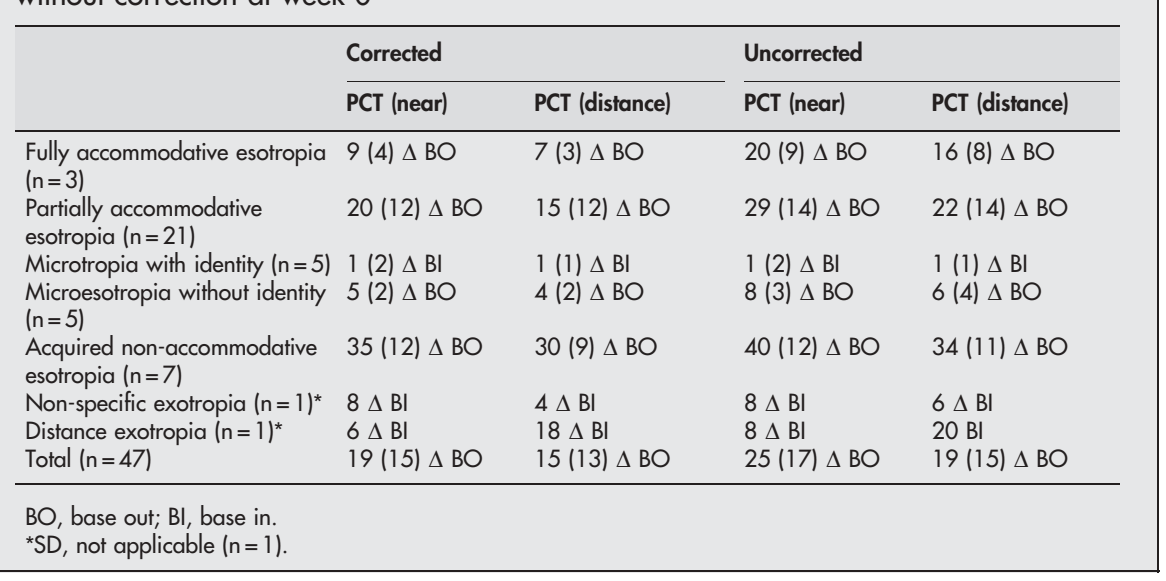

(12\%) children demonstrated less than 1 log line $(0.1)$ of improvement (six mixed; one anisometropic; one strabismic). Five of the eight children had worn spectacles (range 814 weeks) before study entry, although significantly different prescriptions were ordered at the start of the refractive adaptation phase of the study.

Mean (SD; range) interocular difference reduced significantly $(\mathrm{p}=0.01)$ from $0.53(0.4 ; 0.1-1.54)$ to $0.36(0.37 ; 0-$ $1.33)$ a mean reduction in the amblyopic deficit of $0.17(0.17$; 0.00-0.60) log units.

Change in mean (SD) logMAR visual acuity (from week 0 refractive adaptation to best VA measurement) did not differ significantly by amblyopia type (anisometropia 0.29 (0.17); mixed $0.19(0.15)$; strabismus $0.30(0.24)$, table 6$) \mathrm{p}=0.29$, by age ("under 4 years" $(\mathrm{n}=19) 0.23(0.18)$; "4-6 years" $(\mathrm{n}=29) \quad 0.24 \quad(0.20)$; "over 6 years" $(\mathrm{n}=17) 0.16 \quad(0.23))$ $\mathrm{p}=0.38$, or by refractive status (anisometropic hypermetropia 0.24 (0.14), anisometropic astigmatism 0.15 (0.19), isometropic $0.18(0.22), \mathrm{p}=0.35$, table 7$)$.

The mean number of weeks taken to achieve best visual acuity of the amblyopic eye did not differ significantly between amblyopia groups (anisometropia 15.6 (SD 5.6), mixed 14.0 (6.2), and strabismic 15.1 (4.3) p=0.52), or with age ("under 4 years" 14.0 (5.6); "4-6 years" 15.6 (5.9); "over 6 years" $14.4(5.9)) \mathrm{p}=0.63)$. Mean (SD) visual acuities at each 6 weekly stage for each group are shown in table 6 .

\section{Fellow eyes}

Mean (SD) visual acuity in the fellow eyes improved significantly $(\mathrm{p}<0.001)$ from $0.15 \quad(0.13)$ to $0.07 \quad(0.07)$ $\log$ MAR during refractive adaptation, a mean $(\mathrm{SD})$ change in visual acuity of $0.09(0.08) \log$ units. Children with less significant refractive errors in the fellow eye (1.5D or less) demonstrated a $0.04(0.05) \log$ unit improvement. Those with significant refractive errors (1.75D or more) demonstrated a 0.1 (0.07) log unit improvement.

Resolution of amblyopia with spectacles alone

During refractive adaptation the mean (SD), visual acuity of the amblyopic eye in 14 study participants (mean age 5.49 (1.46)) improved from $0.48(0.20)$ to $0.1(0.08)$. These children had an average interocular difference of $0.02(0.05)$ at the end of refractive adaptation and therefore no longer met the study entry inclusion criteria. On this basis they left the study (that is, did not progress to the occlusion phase). Of these 14, nine did not require any further treatment; five had strabismus, five anisometropia, and four had both strabismus

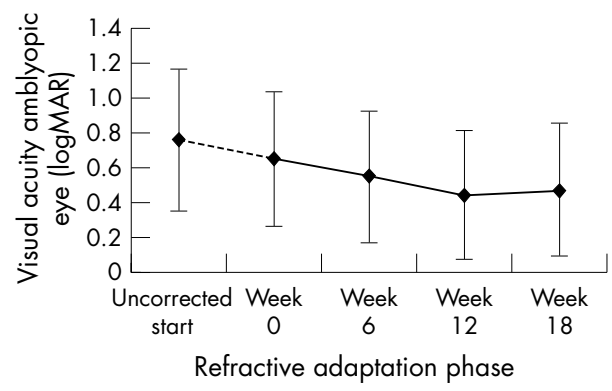

Figure 1 Change in mean (SD) logMAR visual acuity of the amblyopic eye during refractive adaptation. 
Table 6 Mean (SD) logMAR visual acuity during refractive adaptation by amblyopia type

\begin{tabular}{lllll}
\hline & All groups & $\begin{array}{l}\text { Anisometropic } \\
(\mathbf{n}=18)\end{array}$ & $\begin{array}{l}\text { Strabismus } \\
(\mathbf{n}=16)\end{array}$ & Mixed (n=31) \\
\hline Age (years) & $5.1(1.4)$ & $5.5(1.5)$ & $4.2(1.0)$ & $5.2(1.5)$ \\
Uncorrected VA start & $0.77(10.41)$ & $0.57(0.16)$ & $0.79(0.53)$ & $0.90(0.42)$ \\
Corrected VA week 0 & $0.67(0.39)$ & $0.45(0.17)$ & $0.70(0.49)$ & $0.74(0.40)$ \\
Corrected VA week 6 & $0.56(0.38)$ & $0.34(0.16)$ & $0.51(0.43)$ & $0.70(0.39)$ \\
Corrected VA week 12 & $0.45(0.37)$ & $0.21(0.14)$ & $0.37(0.37)$ & $0.70(0.37)$ \\
Corrected VA week 18 & $0.48(0.38)$ & $0.18(0.10)$ & $0.43(0.45)$ & $0.59(0.42)$ \\
Best VA & $0.43(0.41)$ & $0.16(0.1)$ & $0.40(0.41)$ & $0.55(0.41)$ \\
Change in VA & $0.24(0.18)$ & $0.29(0.17)$ & $0.30(0.24)$ & $0.19(0.15)$ \\
Weeks to best VA (within study duration) & $14.7(5.7)$ & $15.6(5.9)$ & $15.1(4.3)$ & $14.0(6.2)$ \\
\hline
\end{tabular}

Table 7 Mean (SD) logMAR visual acuity during refractive by category of refractive error

\begin{tabular}{lllll}
\hline & All groups & $\begin{array}{l}\text { Anisometropic } \\
\text { hypermetropia (n=29) }\end{array}$ & $\begin{array}{l}\text { Anisometropic } \\
\text { astigmatism (n= 18) }\end{array}$ & Isometropia (n= 18) \\
\hline Age (years) & $5.1(1.4)$ & $5.5(1.5)$ & $4.7(1.3)$ & $5.4(1.5)$ \\
Uncorrected VA start & $0.77(0.41)$ & $0.74(0.37)$ & $0.78(0.36)$ & $0.75(0.52)$ \\
Corrected VA week 0 & $0.67(0.38)$ & $0.72(0.38)$ & $0.66(0.32)$ & $0.70(0.50)$ \\
Corrected VA week 6 & $0.56(0.38)$ & $0.59(0.40)$ & $0.61(0.40)$ & $0.40(0.42)$ \\
Corrected VA week 12 & $0.45(0.37)$ & $0.47(0.38)$ & $0.62(0.39)$ & $0.31(0.24)$ \\
Corrected VA week 18 & $0.43(0.38)$ & $0.48(0.45)$ & $0.51(0.40)$ & $0.45(0.43)$ \\
Improvement in VA & $0.24(0.18)$ & $0.24(0.14)$ & $0.15(0.19)$ & $0.25(0.22)$ \\
Weeks to best VA (within study duration) & $13.4(5.7)$ & $14.8(3.86)$ & $13.1(5.8)$ & $14.0(4.0)$ \\
\hline
\end{tabular}

and anisometropia; 13 of the 14 had a significant refractive error in their fellow eye.

\section{DISCUSSION}

This study has quantified the gains in visual acuity attributable to refractive correction and a subsequent period of refractive adaptation as a function of amblyopia type and age of child.

Clinically and statistically significant improvements in the acuity of amblyopic eyes were observed subsequent to 18 weeks of refractive adaptation, which did not differ as a function of type of amblyopia or age (3-8 years). Our study does not allow us to rule out the possibility of further improvement beyond 18 weeks. A significant proportion of children attained acuity in their amblyopic eye such that occlusion therapy was not required. Acuity gains accrued gradually over time taking, on average, 14 weeks and were slightly less (by around one line) than we reported in a much smaller $(n=12)$ cohort. ${ }^{4}$ In contrast, a recent randomised controlled trial of the treatment of unilateral visual impairment reported similar gains in the spectacle only group to those of our present study but only from an initially uncorrected baseline, suggestive of a much smaller effect. ${ }^{5}$

Current clinical practice involves the use of a mainstream therapy (that is, occlusion or penalisation) simultaneously with or in close conjunction (after 4 weeks) with the prescription of spectacles. However, our findings suggest that all children with amblyopia and a significant refractive error will benefit from a longer period of refractive adaptation before any further treatment-which in some cases would no longer be necessary. In others, occlusion could be started with improved visual acuity, possibly enhancing concordance with the treatment.

The full benefit of refractive correction is not immediate, ruling out a simple optical explanation; and a previous study has indicated that practice effects or repeated testing are not a contributory factor. ${ }^{4}$ Refractive correction effectively extends upwards the range of spatial frequency information previously available to the retina and anterior visual pathway and, at least in theory, this could facilitate improvement by promoting, non-competitive, activity dependent recovery. ${ }^{6}$ An analogous effect has been observed consequent upon the removal of monocular infantile cataract. ${ }^{11}$

The pathophysiological mechanisms contributing to the amblyopic deficit differ according to amblyopia type. ${ }^{12}$ In anisometropic amblyopia unilateral blur causes foveal form deprivation and reduced cortical neuronal sensitivity. In strabismic amblyopia there is cortical inhibition of impulses from the fovea of the deviating eye. ${ }^{13}$ For anisometropic amblyopia the correction of refractive error eliminates the unilateral blur which should improve neuronal sensitivity and therefore stimulate visual recovery (see above). However, in the case of the strabismic amblyope with identical refractions in each eye, correction of refractive error may reduce the angle of strabismus but this is unlikely to change cortical inhibition and therefore the mechanism(s) of improvement is unclear. Possibly, in-focus peripheral visual input has a part to play.

Significant gains were also seen in the fellow eyes of children; however, in most participants this was predictable given the presence of a significant refractive error in their fellow eye. Those with none or insignificant refractive errors showed a minimal change within the limits of normal testretest variability. ${ }^{14}$

Although it is a long held clinical belief that amblyopia therapy is more successful in the earlier stages of visual development, ${ }^{15-17}$ (in accord with the presumed end of the visual sensitive period around $6-7$ years $^{18}$ ), the evidence is not conclusive. Recent ATS studies of the Pediatric Eye Investigator Group demonstrated greater gains in visual acuity of those less than 5 years of age for children with severe amblyopia ${ }^{19}$ but no difference for children of another study that had moderate amblyopia. ${ }^{20}$ However, here we demonstrate equal gains for all age groups between 3 and 8 years of age. This is the first time that the visually sensitive period for refractive correction has been examined. 


\section{Authors' affiliations}

C E Stewart, M J Moseley, A R Fielder, Department of Visual Neuroscience, Imperial College London, UK

D A Stephens, Department of Mathematics, Imperial College London, UK

\section{REFERENCES}

1 Reeves B. Taxonomy and epidemiology of amblyopia. In: Moseley MJ, Fielder AR, eds. Amblyopia: a multidisciplinary approach. Oxford: Butterworth-Heinemann, 2002.

2 Kivlin JD, Flynn JT. Therapy of anisometropic amblyopia. J Paediatr Ophthalmol Strabismus 1981;18:47-56.

3 Clarke WN, Noel LP. Prognostic indicators for avoiding occlusion therapy in anisometropic amblyopia. Am Orthopt J 1990;40:57-63.

4 Moseley MJ, Neufeld M, McCarry B, et al. Remediation of refractive amblyopia by optical correction alone. Ophthal Physiol Opt 2002;23:1-4.

5 Clarke MP, Hrisos S, Wright CM, et al. Randomised controlled trial of treatment of unilateral impairment detected at preschool vision screening. BMJ 2003:327:1251-5.

6 Mitchell DE, Gingras G. Visual recovery after monocular deprivation is driven by absolute, rather than relative, visually evoked activity levels. Curr Biol 1998:8: 1179-82

7 Stewart CE, Fielder AR, Stephens DA, et al. Design of the Monitored Occlusion Treatment of Amblyopia Study (MOTAS). Br J Ophthalmol 2002;86:915-19.

8 Stewart CE, Moseley MJ, Stephens DA, et al. Treatment dose-response in amblyopia therapy: the Monitored Occlusion Treatment for Amblyopia Study (MOTAS). Invest Ophthalmol Vis Sci.
9 Bailey IL, Lovie JE. New design principles for visual acuity letter charts. Am J Optom Physiol Opt 1976;53:740-5.

10 McGraw PV, Winn B. Glasgow Acuity Cards: a new test for the measurement of letter acuity in children. Ophthal Physiol Opt 1993;13:400-3.

11 Maurer D, Lewis TL, Brent HP, et al. Rapid improvement in the acuity of infants after visual input. Science 286:108-10.

12 Hess RF. Sensory processing in human amblyopia. In: Moseley MJ, Fielder AR, eds. Amblyopia: a multidisciplinary approach. Oxford: ButterworthHeinemann, 2002.

13 Von Noorden CK. Examination of patient-III Sensory signs, symptoms, and adaptations in strabismus. In: von Noorden GK. Binocular vision and ocular motility: theory and management of strabismus. 5th ed. St Louis: Mosby, 1996:217-223

14 Kheterpal S, Jones HS, Moseley MJ, et al. Reliability of visual acuity in children with reduced vision. Ophthal Physiol Opt 1996;16:447-9.

15 Massie H. Fixing eye for occlusion: survey of 1,000 cases of patients receiving occlusion of the fixing eye. Trans Ophthalmol Soc Aust 1965;24:39-46.

16 Flynn JT, Woodruff G, Thompson JR, et al. The therapy of amblyopia: an analysis comparing the results of amblyopia therapy utilising two pooled sets. Trans Am Ophthalmol Soc 1999:97:373-90.

17 Fulton AB, Mayer DL. Esotropic children with amblyopia: effects of patching on acuity. Graefe's Arch Clin Exp Ophthalmol 1988;226:309-12.

18 Banks MS, Aslin RN, Miyake S. Sensitive period for the development of human binocular vision. Science 1975;190:675-7.

19 The Pediatric Eye Disease Investigator Group. A randomized trial of prescribed patching regimens for treatment of severe amblyopia in children. Ophthalmology 2003;1 10:2075-87.

20 The Pediatric Eye Disease Investigator Group. A randomized trial of patching regimens for treatment of moderate amblyopia in children. Arch Ophthalmol 2003;121:603-11.

\section{The Lighter Side}

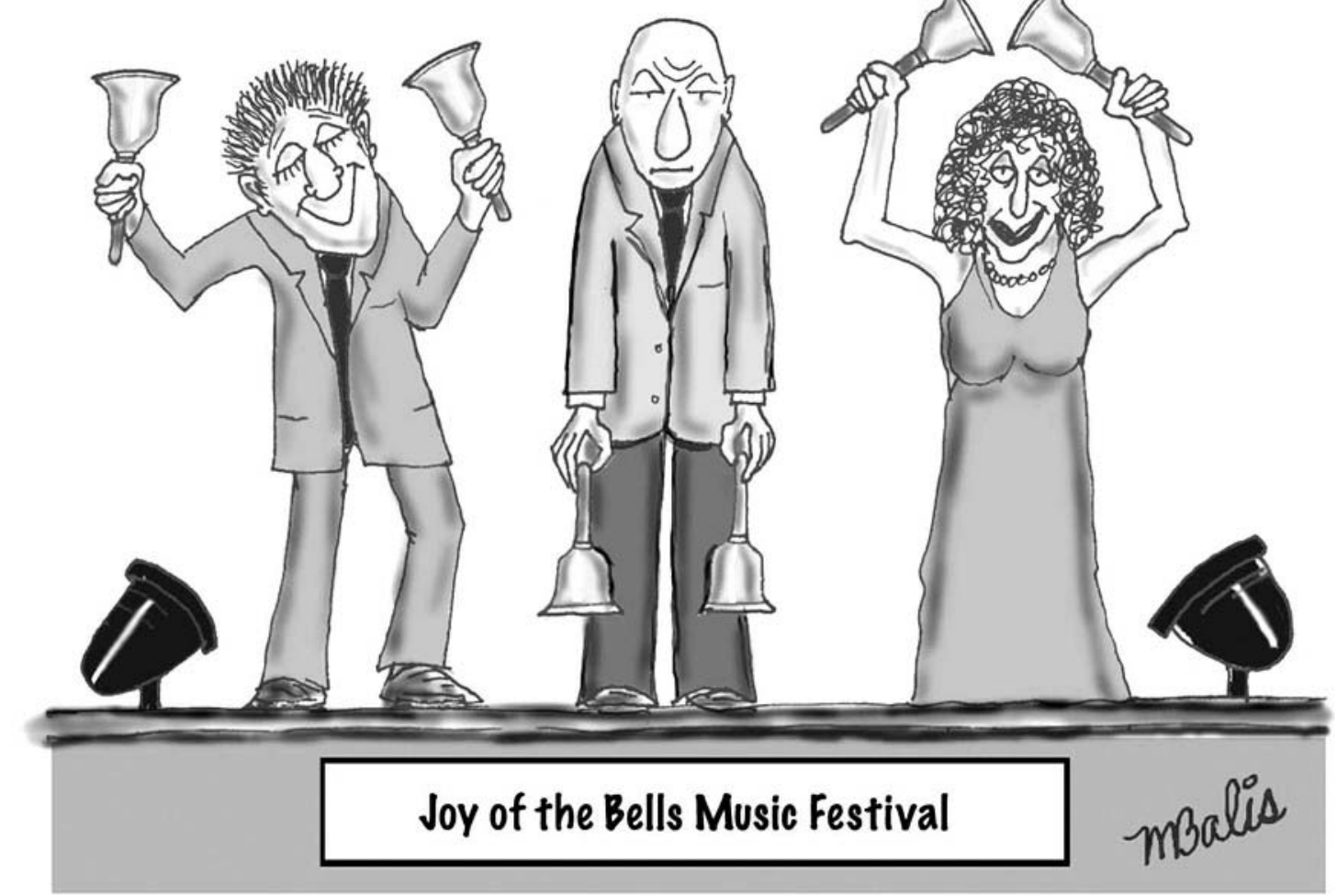

Mr Beadle's episode of Bell's palsy could not have come at a worse time. (C) Michael Balis. 